\title{
Civilización y barbarie, - las construcciones del imaginario nacional: de Rosas a Urquiza
}

Civilization and barbarism, or the constructions of the national imaginary: from Rosas to Urquiza

Civilização e Barbárie ou as construções do imaginário nacional: de Rosas a Urquiza

\section{Nancy Fernández}

UNIVERSIDAD NACIONAL DE MAR DEL PLATA/ CONICET, ARGENTINA

Docente e investigadora de Literatura Argentina en la Universidad

Nacional de Mar del Plata. Doctora en Letras por la Universidad

Nacional de La Plata. Investigadora en Conicet. Autora de

Narraciones viajeras (Biblos, 2000), Experiencia y escritura. Sobre

la poesía de Arturo Carrera (Beatriz Viterbo, 2008), coautora de

Fumarolas de fade. Las poéticas neobarrocas de Severo Sarduy y

Arturo Carrera (Estanislao Balder-UNMDP, 2002) y co-editora

con Juan Duchesne Winter de Arturo Carrera. Antología de la

obra y la crítica. Ha publicado numerosos artículos en revistas

especializadas. Correo electrónico: naferna66@yahoo.com.ar

Artículo de reflexión

Documento accesible en línea desde la siguiente dirección: http://revistas.javeriana.edu.co

doi:10.11144/Javeriana.CL19-37.cbci 


\section{Resumen}

La polémica entre Alberdi y Sarmiento fijan un punto de inflexión en los debates intelectuales y políticos hasta el presente. Nuestro trabajo procura analizar el arsenal retórico, las estrategias discursivas y el sistema de argumentación de ambos autores con relación al presente que protagonizan y a la Historia que juzgan e interpelan.

Palabras clave: Domingo Faustino Sarmiento; Juan B. Alberdi; Argentina

\section{Abstract}

The controversy between Alberdi and Sarmiento set a turning point in the intellectual and political debates up to the present. Our work intends to analyze the rhetorical repertoire, the discourse strategies and the argumentation system of both authors in relation to the present they have a leading role in and the History they judge and question.

Key words: Domingo Faustino Sarmiento; Juan B. Alberdi; Argentina.

\section{Resumo}

A polêmica entre Alberdi e Sarmiento fixam um ponto de inflexão nos debates intelectuais e políticos até o presente. Nosso trabalho procura analisar o arsenal retórico, as estratégias discursivas e o sistema de argumentação de ambos os autores com relação ao presente que protagonizam e à História que julgam e interpelam.

Palavras-chave: Domingo Faustino Sarmiento; Juan B. Alberdi; Argentina.

RECIBIDO: 3 DE ABRIL DE 2014. APROBADO: 27 DE MAYO DE 2014. DISPONIBLE EN LÍNEA: 15 DE ENERO DE 2015.

\section{Cómo citar este artículo:}

Fernández, Nancy. "Civilización y barbarie, o las construcciones del imaginario nacional: de Rosas a Urquiza". Cuadernos de Literatura 19. 37 (2015): 275-284. doi:10.11144/Javeriana.CL19-37.cbci 
Sin DUDA, G UAN D O leemos Cartas Quillotanas bien podemos afirmar que corresponde al carácter de Alberdi medir los efectos que trae aparejada la construcción de un lugar de enunciación. Atañe a Alberdi, intelectual que compartió con Echeverría y con Gutiérrez a lo largo de las décadas, una lectura de la historia que emprende un proyecto cultural y político: fundar la Nación. El espacio común se circunscribe a la librería de Marcos Sastre; allí es donde se pronuncian las primeras lecturas, los discursos inaugurales, con el firme propósito de fijar las pautas que permitan a la Nueva Generación - la así llamada Generación del 37- asumir la distancia crítica que Echeverría deja asentada en su Primera Lectura para el Salón Literario, esto es, la separación respecto de los unitarios de la época rivadaviana como de las sucesivas gobernaciones, desde la etapa criolla hasta Rosas. En ese contexto, su diagnóstico subraya que no se han sembrado las condiciones jurídicas respecto de la conformación institucional de un estatuto y un cuerpo documental que sirva de base a la construcción del Estado. Y en ese momento cabe para Echeverría el lugar de indiscutido mentor, el poeta con las credenciales que le otorga su viaje a París de cinco años, un certificado de legitimidad para colocarse en el lugar de poeta nacional ocupado en construir lengua y tradiciones propias. La poesía entonces, pero también el ensayo, le permitirán tomar distancia para pensar las razones y secuelas sobre el actual estado de cosas, desde la Revolución de Mayo hasta la Generación del 20, el período signado por la figura de Bernardino Rivadavia.

Así, en sintonía con Juan María Gutiérrez, pronuncia sus lecturas cimentando la posición que desmiente una filiación directa con los unitarios. Aquí reside el núcleo del análisis que examina los errores cometidos por quienes no supieron continuar la obra patriótica de los grandes hombres de la Revolución de Mayo, en la época donde las armas eran justicia y necesidad. Ahora faltan ideas, dirá Echeverría, la razón que viene a signar el curso potencial de los hechos, cuando las armas ceden el lugar a la organización de las leyes que, al decir de Halperín Donghi, marca el trayecto de un Estado para consolidar la Nación. Pero aún no hay nada de eso y tampoco quedará el espacio común que Echeverría, Gutiérrez y Alberdi compartían con Pedro de Angelis, la cara letrada del aparato rosista: el periódico La Moda.

Los acontecimientos históricos son sabidos. Rosas construye su poder sobre la base de su genealogía terrateniente y con las fuerzas que arma desde distintos sectores; con la clase popular (negros, peones, esclavos, etc.) imparte la actitud paternalista y protectora del patrón de estancia, mientras con sus pares latifundistas comparte inquietudes que dirige contra Lavalle, la figura que representaba los intereses de los unitarios hasta el desgaste de su figura, que concluye 
por hacerse notorio luego del fusilamiento a Dorrego (sucesor de Rivadavia en la gobernación de la provincia de Buenos Aires, luego de una actitud condescendiente con el Brasil). Ya están dadas las condiciones para que Rosas ingrese al escenario de los hechos y quede fijado como el artífice del orden, el mandatario que puede liderar el país por garantizar los intereses de la oligarquía ganadera en equilibrio con las precarias demandas de los sectores más vulnerables.

Cabe recordar que en tiempos de Rosas, como en los del Virreinato y la Revolución, los términos siempre fueron económicos; morenistas y saavedristas, partidarios del libre comercio con Inglaterra o los defensores del monopolio español. Moreno, con su Representación de los hacendados y con el Plan de operaciones, partidario de la expansión hacia la Banda Oriental y el Sur de Brasil, hace parte de este proceso. Y Rosas sabrá formar sobre ambos sectores, los terratenientes y los emergentes populares, un mutuo apoyo: de esos estratos emerge la Mazorca, el aparato policial del gobierno rosista.

Llegado este punto se hace atendible una vez más el enunciado que David Viñas abrió tempranamente a la polémica: "La literatura argentina empieza con Rosas". La política es el núcleo programático que, a partir de 1938, se extiende para dirimir posiciones definitivamente enconadas en los escritos de los jóvenes del Salón literario, proyectándose en Amalia, de José Mármol, en La cautiva pero sobre todo en El matadero, este último especialmente, constituido como invectiva que Echeverría redacta hacia 1839, quedando oculto hasta el rescate y edición de Juan María Gutiérrez, recién hacia 1971.

El matadero es un texto que media entre el ensayo y el relato, pone en práctica el testimonio alegórico donde el narrador en primera persona traza el diagnóstico sobre el estado en que se encuentra el país. Pero el yo extiende su saber sobre lo real (la política, las leyes, la connivencia entre la Iglesia y el Estado) de acuerdo a las perspectivas espaciales que asume. Así, se acerca hasta ingresar en la escena de la extrema violencia en la que carniceros, mazorqueros, negros y el juez infligen ultraje al unitario en la casilla que, en forma de metonimia, ya es indicio de la totalidad de la República a la cual se está aludiendo. Desde la perspectiva de Viñas, es a partir de Rosas cuando se acentúa el proceso donde sangre y barro son marco y repertorio de una fiesta que tiene a la violencia como centro. Ello será motivo articulador de series y tradiciones en el sistema de la literatura argentina. Pero no habría que desatender que Echeverría publica $E l$ dogma socialista, un tratado político, social y económico cuyo autor se preocupa por asentar la necesidad de armar los medios para hacer producir a las tierras y al desierto que decrece en valor pecuniario cuanto más cerca se hallan de las fronteras al asedio de los indios. Si hubo que esperar años para leer El matadero, 
no deja de ser cierto que su autor dejó visiblemente, en forma embrionaria, el sistema de ideas que giran en torno a civilización y barbarie, aunque haya sido Domingo F. Sarmiento quien en 1845 titulara su célebre libro (publicado al comienzo en forma de folletín) Facundo. Civilización y Barbarie. Es en El matadero donde anida la historia del solemne unitario que enfrena a la masa popular, cuya lengua el narrador (alter ego e imagen de autor) estiliza mediante giros que le son ajenos. De ahí el rescate que Piglia hace en su libro La Argentina en pedazos. Y, como decíamos, se podría decir que es la violencia el síntoma que constituye el centro de las representaciones culturales argentinas, cuya constante operatividad reside precisamente en su carácter de tópico y de motivo, en tanto materia que organiza y estructura el imaginario nacional.

La polémica entre Alberdi y Sarmiento constituye un punto de inflexión en las letras argentinas, en el sistema por dirimir el ideario que no deja de manifestar los síntomas más emergentes y constantes del dilema nacional. Y ya desde el marco textual que proponen las Cartas Quillotanas, se plantea un sistema de enunciación que atañe al género de escritura, puesto en función de un plan político. Si el texto que Alberdi publica en Quillota, Chile, parece dar paso a una acusación en posición ofensiva contra el desertor de Urquiza y el pacto de San Nicolás, con la inclusión de la "Dedicatoria de la campaña en el Ejército Grande" - "Mi querido Alberdi"-, Sarmiento es colocado en el comienzo del conflicto como agitador irredento con delirios de megalómano. El núcleo de las Cartas, nomenclatura que por otro lado merece una disquisición aparte, es, efectivamente, la separación de Sarmiento que luego de la batalla de Caseros en $195^{2}$ pone en el centro de la escena a Justo José de Urquiza como el libertador de un país sumido en el yugo de la tiranía durante casi veinte años. Sarmiento, entonces, es enjuiciado como quien proscribe los respaldos ganados legítimamente en el proyecto mancomunadamente civilizador; Buenos Aires se muestra renuente a acatar la ley que demanda su integración al resto de las provincias en un proyecto federal que fomenta la libre navegación de los ríos y la distribución equitativa de las rentas aduaneras. Los unitarios centralizados en torno del puerto agitan sus viejas banderas sin concesiones, por lo que Urquiza muy pronto restablece el cintillo punzó no solamente como símbolo sino como el sustrato imaginario que supone efectos reales a la hora de organizar la República y un Estado que la sostenga.

Recordemos de paso que fue el filósofo contemporáneo Castoriadis quien saca a la luz la doble composición de la categoría de imaginario, lo que podemos ver funcionar en tanto la Nación está cimentada en un doble plano de proyección cultural, simbólica - fabulaciones, mitologías, narraciones historiográficas y hechos documentados - y a la vez real, en la dimensión performativa de los efectos 
que concluyen por constituir discursos y posiciones acordes a una significación colectiva instalada históricamente. Porque si para Alberdi el cintillo punzó es un hecho menor, para Sarmiento es el signo que hiperbólicamente anuncia una nueva dictadura. Sin embargo, Alberdi propone un juego de cartas, la treta o el truco de un intelectual al servicio del Estado que sabe esgrimir el saber legislativo de acuerdo con marchas y contramarchas de los vaivenes políticos, del campo del poder o de las variables de la coyuntura.

Es así como Sarmiento queda sindicado como el iniciador de la polémica cuando Alberdi incluye en su libro Cartas Quillotanas una advertencia que, de modo preliminar, le marca al lector signado en tercera persona el rumbo a seguir una vez conocidos los hechos que motivan la presente publicación. Esa breve nota deja constancia de, por un lado, la separación táctica entre el intelectual que adscribe al nuevo programa, y la opinión pública a la que se dirige, en el justo equilibrio de quien conoce a fondo el conjunto de decisiones que dan forma al Gobierno actual. Se diría que la impecable retórica argumentativa y racional de Alberdi da forma al estado público de los hechos. Los lineamientos desarrollados en sus Bases -en concordancia con su Fragmento preliminar al estudio del Derecho- configuran un proyecto y una práctica que pretende poner orden y organización republicana a la Confederación argentina. Recién en la tercera de sus cartas comienza a avizorarse la sutileza irónica que no sólo hiere la autoestima de Sarmiento ("A todo lo que aparecía de su pluma, nuestra palabra de orden era bravo, estupendo! Lo aplaudíamos sin leerlo. A mí me sucedió eso de ordinario"), sino que comienza a horadar la esfera privada aludiendo al rol de Sarmiento en la prensa como periodista a sueldo, cuyo mérito no está exento de mediar entre deberes patrióticos, intereses personales y "necesidades satisfechas". La tercera de las cartas es la estocada que procura derribar a Sarmiento de su rol indiscutible: el de escritor. Así que, dirá Alberdi, mil volúmenes de crítica no tienen la eficacia de la batalla de Waterloo en la caída de Napoleón, enunciando a modo de pregunta retórica - ya que no aguarda respuesta - lo que sabe de antemano: la prensa no provocó la caída de Rosas. O mejor, si la prensa hubiera derrocado al poder enemigo, Sarmiento habría compartido el triunfo con Varela, Alsina, Mármol e Indarte, restando peso al personalismo del autor de Recuerdos de provincia. Y es en la misma carta donde Alberdi ejercerá su función de crítico lector cuando se dispone a indagar las motivaciones que la coyuntura, el poder y la política imprimen en las sucesivas ediciones del Facun$d o$. Desde esta perspectiva, Sarmiento corrige su texto siguiendo las indicaciones de Alsina. Así, en la primera edición, la introducción equilibraba una crítica y un análisis entre una teoría determinista del caudillaje ("como expresión normal de la vida argentina") más dos capítulos finales acerca del Gobierno unitario cuya falta 
de sentido práctico acusaba cierta impericia. Ya en la segunda edición estos dos capítulos desaparecen por consejo de Alsina y protección de intereses partidarios. La supresión concluye con la biografía de Facundo y con su muerte.

Conjurando el fantasma de la maledicencia, Alberdi y Sarmiento cruzan ataques en base a las remuneraciones y honorarios percibidos. Si el primero merodea la intimidad del contrincante midiendo los límites del decoro y la eficacia del objeto de controversia, en la cuarta carta finalmente ensaya una suerte de disculpa o advertencia por exponer en primera persona vicisitudes personales y ajenas. Aquí es donde Alberdi deja filtrar un discurso por cuyas grietas asoman las mezquindades, tras los telones del poder; será allí donde Alberdi bordea, queriéndola evitar, la jactancia de quien se arroga la propiedad de las ideas. Sin embargo, su individualidad la resguarda en la garantía del grupo al que perteneció desde la década del 30. Así defenderá la preeminencia de la Generación del 37 , con Echeverría y Gutiérrez a la cabeza, en cuyo seno se gestaban las ideas acerca de la civilización y la barbarie.

Si en las Ciento y Una Sarmiento acepta su función de "periodista a sueldo", la concesión funciona en doble sentido; por un lado como autodefensa y por otro como la irónica victimización, prolegómeno al panegírico en primera persona:

$\mathrm{Al}$ excmo. Señor enviado plenipotenciario efectivo cerca de los diarios de Valparaíso y ad referéndum, cerca del gobierno de Chile, doctor don Juan Bautista Alberdi.

En la olla podrida que ha hecho usted de Argirópolis, Facundo, La Campaña, etcétera, etcétera, condimentados sus trozos con la vistosa salsa de su dialéctica saturada de arsénico, necesito poner orden para responder y restablecer cada cosa en su lugar. Por ahora me basta fijar las cuestiones primordiales. ¿De qué se trata en sus cartas quillotanas? De demoler mi reputación, ¿Quién lo intenta? Alberdi.

¿Qué causa lo estimula? Ser empleado para ello.

¿Cómo le vino ese empleo? Negociándolo por medio de Gutiérrez, a trueque de escribir en Chile. ¿Cuál es el resultado de su libro? Dejar probado que no soy nada y que usted lo es todo.

Todo esto necesitaré tener presente en estas primeras consideraciones.

Además, Alberdi es un abogado culto y no periodista de profesión. Yo no soy sino periodista a sueldo, un "gaucho malo" de la prensa.

En la profusión temperamental de la escritura sarmientina obran las réplicas discursivas que se apropian de la palabra de Alberdi desviándola de sus lineamientos originales. Porque si bien asume su rol como periodista que percibe 
un pago por su trabajo (el intelectual que interviene en política y que escribe libros es también un profesional), se autoincrimina en un insulto que Alberdi pronuncia de manera abstracta, categórica, impersonal. Alberdi se refiere a la "prensa gaucha" como a la "prensa enana" y a la "prensa venenosa", estadios opuestos y obsoletos frente al carácter de lo nuevo que subraya el jurista. Ya que, tal como lo anuncia, procurará hacer un estudio con cuidado y respeto, resultando una impugnación que provoca en Sarmiento una respuesta febril, enconada y meticulosa. Pero la contrarréplica se genera en tanto respuestas no solicitadas entre uno y otro, en tanto enunciados que presuponen posiciones tomadas y manifestaciones subrepticias; de este modo, si Sarmiento dictamina una conclusión acerca del lugar que le reserva Alberdi, el autor del Facundo prescribe la anulación del saber que lo legitima, invalidando hasta las últimas consecuencias el título de abogado. La contrarréplica que supone la refutación primera de Alberdi en sus Cartas, cuando advierte que en Campaña en el Ejército Grande su autor ha excedido los límites de los saberes, los territorios implícitamente distribuidos entre hombres de letras que realizaban un proyecto de nación. Como buen lector, Alberdi percibe que Sarmiento ha invadido su propio terreno: los derechos, la organización institucional, la Constitución.

El "lector", entonces, conocerá los detalles de un conflicto en ciernes con la "Dedicatoria de la campaña en el Ejército grande" que Alberdi extrae del libro de Sarmiento para incluirlo como prueba de sus argumentos y razón que justifica su exposición. Es Sarmiento quien invade el saber donde opera Alberdi, aconsejándolo que se circunscriba al plan de regeneración de la patria, consignado en las Bases. Y mientras en esta dedicatoria Sarmiento apela a su función práctica y testimonial alegando que la misión lo encontró en el teatro de los hechos, a su vez defiende su rol de intelectual que milita en la prensa y en la guerra, cuestiones en las que Alberdi no escatimará razones para demoler con retórica cuidada, medida y calculada, estimando que su texto procura ser un estudio tan "desapasionado" como racional. Lo que parece quedar descolocado en el obrar de Sarmiento es una supuesta congruencia que a los ojos de Alberdi no es otra cosa que una empecinada frustración por no ocupar el primer plano de la historia, una obstinada ceguera que le impide ver los nuevos roles de la prensa, del intelectual, del político adecuados al contexto actual. Una nueva mirada que requiere un nuevo posicionamiento no sólo frente a Buenos Aires y sus históricos privilegios (económicos, geográficos, políticos) sino también frente al campo, a las provincias, al gaucho y al caudillo, para el cual Alberdi pide garantías. La adaptación a los tiempos actuales es esgrimida por Alberdi y condenada por Sarmiento, quien refrendando su coherencia refuta el pragmatismo de Alberdi reprochándole actuar de acuerdo con sus propios 
intereses. Su nombramiento como Ministro Plenipotenciario en Chile lo aleja de la verdad genuina de la causa nacional. Campaña en el Ejército grande supuso un libro orgánico con el que Sarmiento ingresa en la arena política, de modo que el uso que Alberdi hace de su cita, mantiene al autor de las Bases en la esfera pública. Aquí ingresamos en la cuestión del género, tan solo será la Cuarta Carta donde el abogado incurre en la primera persona, donde habla de sí mismo para desalojar los rumores que manchen su reputación y su prestigio. Hasta ese momento, Alberdi sistematiza una polémica y se construye como lector con una mirada sagaz que sabe observar el ascendente de Alsina en las posteriores ediciones del Facundo respecto de las supresiones que Sarmiento efectúa de sus primeras críticas a los unitarios (en sintonía con los jóvenes ilustrados de la Generación del 37). Alberdi es perspicaz para leer el reacomodamiento de su adversario en las filas del unitarismo y la construcción de la figura pública que Sarmiento diseña en sus libros, especialmente en Recuerdos de provincia.

Pero esa serie de acusaciones y alegatos que constituyen la diatriba entre uno y otro, no consisten en un genuino intercambio epistolar. La cuestión del género toma la convención de la carta y una segunda persona que determina el lugar del supuesto destinatario, pero a decir verdad, ni uno ni otro esperan respuesta alguna ya que se trata de posiciones fijadas de antemano y de doctrinas políticas que vienen a sostener en miras de un país. Si se invoca el nombre propio del contrincante es a título de convención retórica que no hace otra cosa que poner en evidencia la ruptura de pactos pasados. Mientras el discurso de Alberdi procura un tono impersonal acorde al equilibrio de un hombre realista y práctico que advierte el cambio político que se sostiene en un proyecto de largo alcance, las palabras de Sarmiento son cataratas de insultos con nombre, apellido y apodos denigrantes. En este sentido, la lógica alberdiana procura demoler con cuidado el edificio que Sarmiento hizo de su persona, relativizando su rol de boletinero a los limitados méritos que cosechara en tiempos de Rosas. El abogado lo coloca en el lugar de la prensa gaucha ("prensa enana, prensa venenosa") cuidando de omitir señales explícitas que Sarmiento, en sus Ciento y Una, tomará como acusaciones personales y en su contra. Es el sistema de argumentación prescriptiva y replicante que convierte a la escritura de Alberdi en un análisis del momento actual proyectado sobre la historia del país; es una perspectiva a largo plazo y con mirada retrospectiva que procura leer sobre el trasfondo del pasado el rechazo del pacto de San Nicolás. Entre tanto, la escritura sarmientina prolifera en disquisiciones del pasado y del presente que atañen al sistema del poder, a los numerosos personajes que cumplen una función en la coyuntura y no en la generalidad conceptual de la Historia. Sarmiento, que retruca a Alberdi el querer dejarlo al margen de la Historia, se concentra en 
los sucesos que les son contemporáneos y que pertenecen a las tramas políticas de cargos, representaciones, embajadas y ministerios. Estado y Nación quedan al amparo del saber legislativo, para lo cual Alberdi debe citar sus textos en defensa propia. Entre tanto, las Giento y Una constituyen los escritos que median la autolegitimación en primera persona con todas las estrategias ficcionales que le conocemos desde Facundo: anécdotas improbables, discursos ajenos citados entre comillas, simulando en estilo directo, la veracidad testimonial de quien fue testigo de los hechos. Todo en Sarmiento seguirá la línea de un perfil de autoridad, basada en sus escritos y en su intervención política, en el país y en el exilio. Autoridad y autovalidación de la palabra que procura compensar la acción clandestina de Sarmiento, al margen de la ley urquicista.

\section{Obras citadas}

Altamirano, Carlos y Beatriz Sarlo. Ensayos Argentinos. De

Sarmiento a la vanguardia. Buenos Aires: Ariel, 1997.

Bertoni, Lilia Ana. Patriotas, cosmopolitas y nacionalistas. La construcción de la nacionalidad argentina a fines del siglo XIX.

Buenos Aires: Fondo de Cultura Económica, 2001.

Castoriadis, Cornelius. La institución imaginaria de la sociedad. Barcelona: Tusquets, 1993.

Gasquet, Axel. "Oriente al Sur". El orientalismo literario argentino de Esteban Echeverría a Roberto Arlt. Buenos Aires: Eudeba, 2007.

Halperín Donghi, Tulio. Una nación para el desierto argentino.

Buenos Aires: Editores de América Latina, 2004.

Mayer, Marcos. "Estudio preliminar". Las Ciento y Una; Cartas Quillotanas. Domingo

F. Sarmiento y Juan B. Alberdi. Ed. Marcos Mayer. Buenos Aires: Losada, 2005.

Mayer, Jorge. El pensamiento vivo de Alberdi. Buenos Aires, Losada, 1983.

Oslak, Óscar. La formación del Estado argentino. Buenos

Aires: Editorial de Belgrano, 1985.

Prieto, Adolfo. La literatura autobiográfica argentina. Buenos Aires: CEDAL, 1982.

Romero, José Luis. Breve historia de la literatura argentina.

Buenos Aires: Fondo de Cultura Económica, 1999.

Sarmiento, Domingo Faustino y Juan B. Alberdi. Las Ciento y Una; Cartas

Quillotanas. Ed. Marcos Mayer. Buenos Aires: Editorial Losada, 2005.

Viñas, David. Literatura argentina y política. De los jacobinos porteños

a la bohemia anarquista. Buenos Aires: Sudamericana, 1995.

Weimberg Félix. De la "ilustración" a la reforma universitaria, ideas y protagonistas.

Buenos Aires: Santillana-Academia Nacional de Educación, 2001. 